\title{
Middle school students' conceptual understanding of earthquakes
}

\author{
Döne Toprak-Dereli ${ }^{1}$ and Funda Savaşc1-Açıkalın ${ }^{2, *}$ \\ ${ }^{1}$ Graduate Student, Istanbul University-Cerrahpasa Graduate School, Istanbul, Turkey \\ ${ }^{2}$ Associate Professor, Istanbul University-Cerrahpasa Hasan Ali Yucel Faculty of Education, Istanbul, \\ Turkey
}

\begin{abstract}
The purpose of the study was to investigate middle school students' conceptual understandings of earthquakes. Data were collected by using Understanding Earthquakes Test [1] and semi-structured interviews. Participants were a total of 1024 middle school students from the fifth to the eighth grade studying at ten different schools in Istanbul. Semi-structured interviews were conducted with thirty six students selected based on their test scores for three levels of understanding as high, middle, and low level. Findings of the current study indicated that students have lack conceptual understanding of earthquakes with many alternative conceptions. Students mostly from all grade levels seemed to have more scientific understanding in terms of protecting ways from earthquakes damage rather than explaining what earthquakes are and how earthquakes happen.
\end{abstract}

\section{Introduction}

Earthquakes are one of the destructive natural disasters for many countries all over the world. Turkey is one of the most seismically active regions on the earth due to the complex plate interaction among Arabia, Eurasia and Africa [2]. The most active fault zone in Turkey passes close to Istanbul and other major urban cities [3]. Moreover, more than half of the country falls under the earthquakes zones while almost all of the population lives in hazardous earthquake areas in Turkey [4].

Earthquakes are unavoidable natural disasters but the damage of earthquakes can be reduced by increasing people's knowledge and awareness about earthquakes [5-9]. There are have been many national and international studies investigating students' conceptual understandings of earthquakes in the literature [10-14]. Research indicated that both teachers and students have lack scientific knowledge about earthquakes with many misconceptions $[1,4,5,8,10,15-20]$. A number of misconceptions were identified in the literature and some of them were listed as follows:

- Earthquakes occur in warm cities.

- Cracks that are resulted with heating earth by sun cause earthquakes.

\footnotetext{
Corresponding author: fsavasci@istanbul.edu.tr; This study is a partial of the first author’s Master thesis.
} 
- Volcanic eruptions create earthquake.

- The source of earthquakes are weather events.

- Sun, thunder, rain, wind, heat, landslide and avalanche cause earthquakes.

- Earthquakes more likely occur near to islands.

- God creates earthquakes as a result of people's crime.

- The reasons of earthquakes are human activities (environmental pollution, soil pollution) $[10,11,13,14,17,19-22]$.

It is necessary to study students' conceptual understandings about earthquake in order to teach scientific understanding of earthquakes [19]. If students learn what earthquakes are and how they occur as well as how they protect themselves from the damage of earthquakes, it is possible to build earthquake literate society [5, 19, 23]. Therefore, the purpose of the study was to investigate middle school students' conceptual understandings in terms of not only what earthquakes are, how they occur but also how they protect themselves from the damage of earthquakes. The current study also consisted of a large sample size of middle school students studying at different grade levels in Istanbul and was conducted by a mixed research methodology including quantitative and qualitative data collection. As a result, it is expected to add significant contribution to the literature. The following research questions were designed;

1. How are fifth, sixth, seventh, and eighth grade students' conceptual understandings of earthquakes in terms of what earthquakes are, how they occur, what are their effects, and how people protect themselves from the damage of earthquakes?

2. Is there any significant difference of students' conceptual understanding in terms of grade levels?

\section{Methodology}

\subsection{Data Collection}

Mixed research methodology was conducted in order to investigate research questions in the current study. Data were collected by using Understanding Earthquakes Test [1] and semi-structured interviews. The test consisted of 60 questions with three-point Likert scale under four main categories: what earthquakes are (Part A), how earthquakes happen (Part B), how earthquakes affect other things (Part C), and how to protect ourselves from earthquakes (Part D). Thirty-six students selected based on their test scores as three levels as high, middle, and low were invited to semi-structured interviews. Each interview session took 15-20 minutes and students were asked about what earthquake is, how and why earthquake happens, how to protect earthquake damages. All interview records were transcribed before analyzing data.

\subsection{Participants}

Data were collected from a total of 1024 middle school students from the fifth to the eighth grade studying at ten different schools in Istanbul. School district permission was obtain before collecting data. All students were voluntarily participated in the study.

\subsection{Data Analysis}

Quantitative data was analyzed by using SPSS. Percentage and frequency of student responses for each question were calculated as descriptive statistics. Middle school 
students' conceptions of earthquakes were analyzed in terms of four major categories including definition of earthquakes (Part A what earthquakes are), the process of earthquakes (Part B how earthquakes happen), the effects of earthquakes on other things (Part C how earthquakes affect other things), and possible way for protecting people from earthquake damage (Part D how to protect ourselves from earthquakes). In order to analyze if there is any significant difference among students' conceptions in terms of grade level, ANOVA test was calculated. Student responses from semi-structured interviews were coded and categorized by using an inductive approach.

\section{Findings}

Findings of the current study indicated that middle school students have lack of scientific understanding of earthquakes. Firstly, both test scores and student responses in interviews indicated that middle school students in the current study had difficulty defining what earthquakes are. Figure 1 shows some examples of questions related to what earthquakes are and percentage of student responses to those questions. As seen in Figure 1, most of the students responded questions related to what earthquakes are as undecided. Many of them seemed to be unsure that earthquakes created seismic waves, or they occur on faults.

A7: Earthquakes are a release of energy stored in rocks.

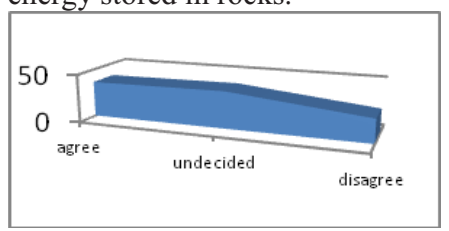

A12: Earthquakes only come to fruition in the world's crust

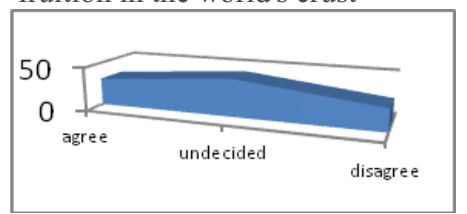

A10: Earthquakes occur on faults.

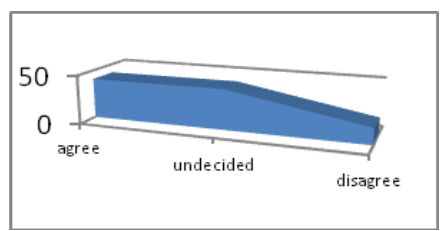

A14: Earthquakes create seismic waves.

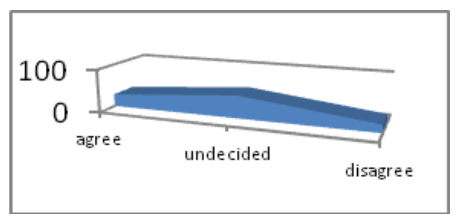

Figure 1 Percentage of students' responses related to questions of what earthquakes are

Figure 2 gives some examples of questions related to how earthquakes happen and percentage of student responses. As seen in Figure 2, middle school students in the current study were not sure about their responses so they did not seem to know that earthquakes are caused by release of energy stored in rocks or by the movement along faults.

B1: Earthquakes are caused by release of energy stored in rocks.

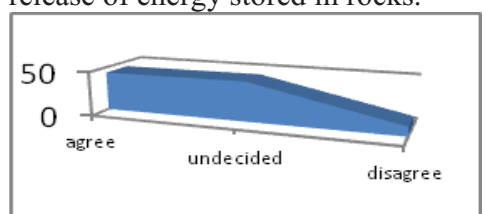

B2: Earthquakes are caused by the movement along faults.

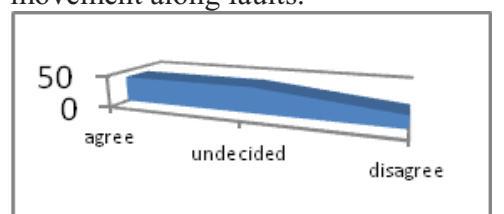

Figure 2. Percentage of students' responses related to questions of how earthquakes happen 
B5: Earthquakes are caused testing.

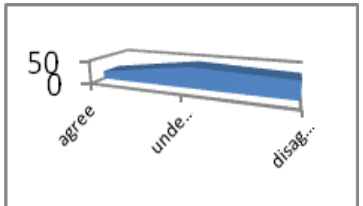

B6: Earthquakes are caused by the Earth's core moving to the surface.

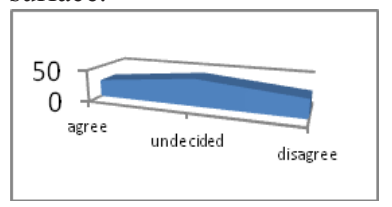

B14: Earthquakes are by nuclear caused by tides.

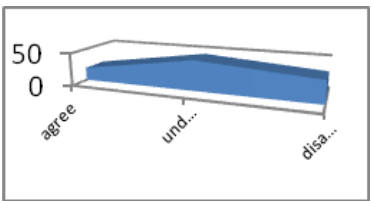

Figure 3. Percentage of students' responses related to unscientific statements of how earthquakes happen

Students in the current study seemed to have many misconceptions related to how earthquakes happen. In Figure 3, students seemed to be undecided that that testing, Earth's core moving to the surface, or tides can be reasons for earthquakes. Moreover, as seen in Figure 4, most of the students agreed with that deep noises vibrations or bad coming from under the ground can be reasons for earthquakes.

B13: Earthquakes are caused by the deep noises vibrations.

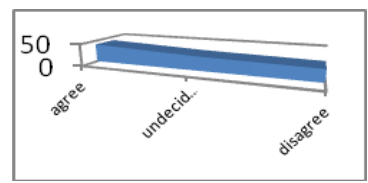

B15: Earthquakes are caused by bad coming from under the ground.

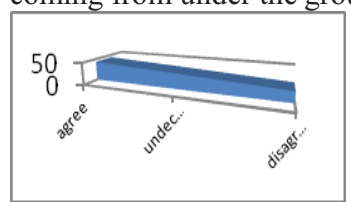

Figure 4. Percentage of students' misconceptions related to how earthquakes happen

Figure 5 shows percentage of students' responses of the effects of earthquakes. As seen in Figure 5, students seemed to have adequate knowledge about observable influences of earthquakes to daily life and social life. It is founded that students do not have clear understanding between earthquakes and volcanos. Many students agree with the items C3, C14, C15 about predictions of earthquakes as similar to common beliefs in society.

C2: Earthquakes can move faults.

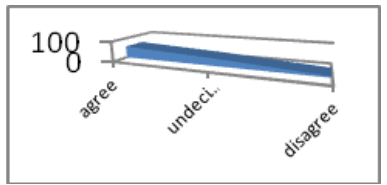

C7: Earthquakes can change the water level in wells.

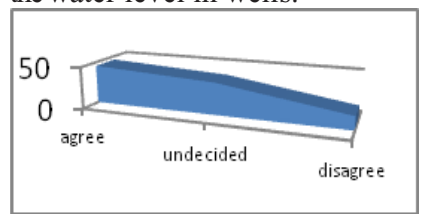

C5: Earthquakes can make people have trouble walking

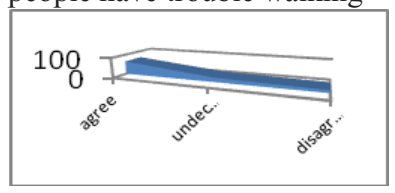

C8: Earthquakes can shape the physical features of land.

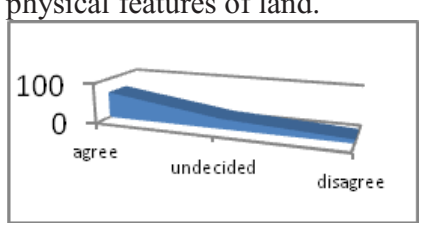

C6: Earthquakes can push move houses into the soil

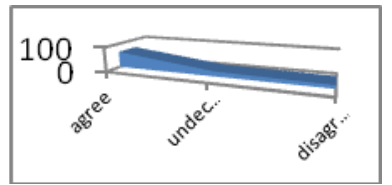

C13: Earthquakes can cause volcanoes.

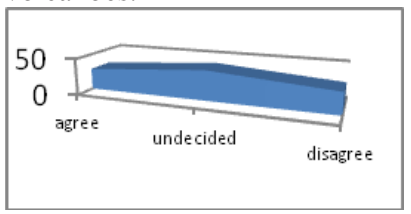


C3: Earthquakes can cause dog to bark just before it happens

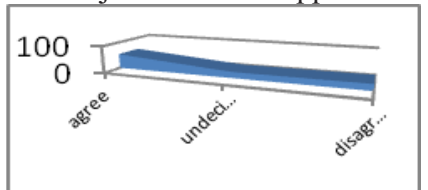

C14: Scientist can predict earthquakes.

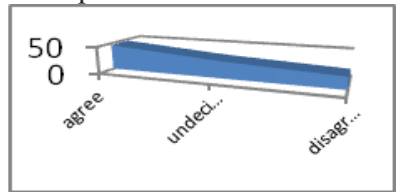

C15: Animals can predict earthquakes

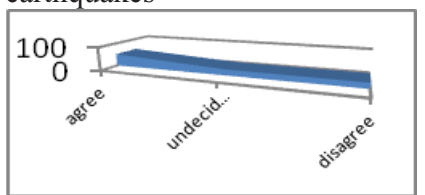

Figure 5. Percentage of students' responses related to the effects of earthquakes

Figure 6 indicates percentages of students' responses related to ways of protecting from earthquakes. Almost the half of the students disagreed with the items D2, D4, D10, D12 that include nonscientific ways of protection from earthquakes. However, students seemed to be not sure with respect to the items D6 and D7.

D2: Before earthquakes we should move heavy objects to high shelves because heavy objects can withstand quakes.

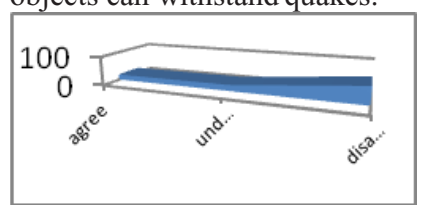

D10: During earthquakes we should stand under a tree.

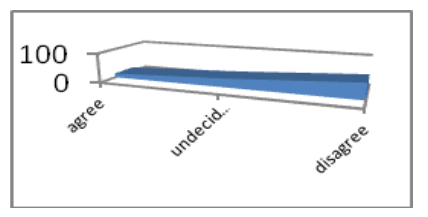

D6: Scientist can accurately predict earthquakes before it happens.

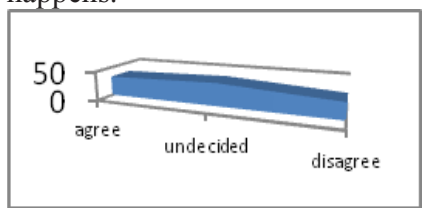

D4: Before earthquakes we should place beds by large windows so one can easily escape from the window.

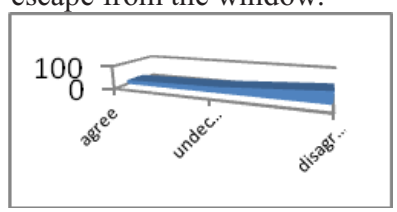

D12: During earthquakes if you find yourself indoors it is unusually better to rush outside.

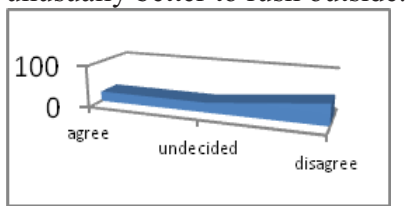

D7: During earthquakes we should hold on to something metal.

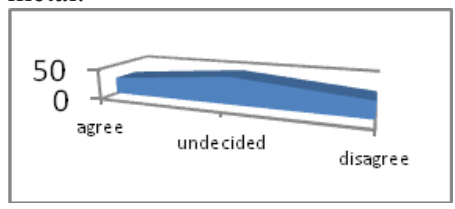

Figure 6. Percentage of students' responses related to the ways of protecting from earthquakes

In order to response research question 2, ANOVA test was done to investigate if there is any significant difference among students at different grade levels. Table 1 shows the result of statistical analysis with respect to what earthquakes are. As seen in Table 1, there is a statistical difference of students' conceptions of what earthquakes are in terms of grade level. 
Table 1. Grade level comparison in terms of students' conception related to what earthquakes are

\begin{tabular}{lllllll}
\hline & SS & SD & Mean square & F & p & Significance \\
\hline Between groups & 61,13 & 3 & 20,64 & 4,45 &, 004 & $8-5,8-6,8-7$ \\
Within groups & 4723,28 & 1019 & 4,63 & & & \\
Total & 4785,21 & 1022 & & & & \\
\hline
\end{tabular}

Table 2 shows the result of statistical analysis with respect to how earthquakes happen. As seen in Table 2, there is no statistical difference of students' conceptions of how earthquakes happen in terms of grade level.

Table 2. Grade level comparison in terms of students' conception related to how earthquakes happen

\begin{tabular}{llllllc}
\hline & SS & SD & $\begin{array}{l}\text { Mean } \\
\text { square }\end{array}$ & F & p & Significance \\
\hline Between groups & 59,41 & 3 & 19,80 & 3,76 &, 011 & - \\
Within groups & 5369,30 & 1020 & 5,26 & & & \\
Total & 5428,71 & 1023 & & & & \\
\hline
\end{tabular}

Table 3 indicates the result of statistical analysis with respect to effects of earthquakes. As seen in Table 3, there is a statistical difference of students' conceptions of effects of earthquakes in terms of grade level.

Table 3. Grade level comparison in terms of students' conception related to effects of earthquakes

\begin{tabular}{lllllll}
\hline & SS & SD & $\begin{array}{l}\text { Mean } \\
\text { square }\end{array}$ & F & p & Significance \\
\hline Between groups & 269,56 & 3 & 89,85 & 12,16 &, 000 & $8-5,8-6,8-7$ \\
Within groups & 7535,31 & 1020 & 7,38 & & & \\
Total & 7804,88 & 1023 & & & & \\
\hline
\end{tabular}

Table 4 shows the result of statistical analysis with respect to ways of protection from earthquake damage. As seen in Table 4, there is a statistical difference between the fifth and the eighth grade students' conceptions of ways of protecting from earthquake damage.

Table 4. Grade level comparison in terms of students' conception related to ways of protection from earthquakes

\begin{tabular}{lllllll}
\hline & SS & SD & $\begin{array}{l}\text { Mean } \\
\text { square }\end{array}$ & F & p & $\begin{array}{l}\text { Significance } \\
\text { discrepancy }\end{array}$ \\
\hline Between groups & 38,38 & 3 & 12,79 & 2,82 &, 038 & $8-5$ \\
Within groups & 4625,58 & 1020 & 4,53 & & & \\
Total & 4663,96 & 1023 & & & & \\
\hline
\end{tabular}

\section{Discussion}

This study investigated middle school students' conceptual understanding of earthquakes. Findings of the current study indicated that middle school students have difficulty to understand earthquake scientifically. Many students did not have scientific understanding 
of causes of earthquakes such as fault lines, seismic waves, and released energy stored in rocks. Some of the students believed that volcanism, tides, bad vibration and nuclear test can be causes of earthquakes. It is identified that students have belief about more occurrence of earthquakes in seas, dry regions and islands. Some of the students thought human actions like cutting trees, global warming, environmental pollution, over urbanization as causes of earthquakes. The findings of the research are similar with the results of previous studies $[1,10,11,12,13,14,19,20]$. Findings of the current study indicated that some of the students believe that some animals can feel the earthquakes before it happens and scientist can predict earthquakes. Some of them stated that planting works, keeping environment clean, and less construction of buildings are necessary in order to prevent earthquakes. Students generally have lack of knowledge about causes of earthquakes and prediction about earthquakes. However, students at the upper grade level are more likely to have scientific understanding of earthquakes than those at the lower grades. The most difficult concept for students to understand were causes of earthquakes. This findings was consistent with the previous studies $[6,18,19]$. It is not surprising since science education curriculum does not cover sufficiently earthquakes topics.

\section{Conclusion}

The findings of the current study offers valuable implications for educators and future researchers. First of all, curriculum developers should include earthquake concepts especially the process about causes of them to the curriculum of primary and middle school since it is necessary to teach these concepts especially in Turkey. Secondly, teachers should have more scientific understanding of earthquakes and focus on more earthquake concepts in science classroom by a variety of instructional materials and methods. Finally, teacher education programs should organize seminars, conferences and other programs to increase knowledge and awareness of pre-service teachers and students.

\section{Acknowledgment}

This study is a partial of the first author's thesis. The project was supported by Istanbul University with a project no (will be added).

\section{References}

1. A. Oğuz, Unpublished PhD Dissertation Ohio State Uni. (2005)

2. O. Tan, M. C. Tapırdamaz, \& A. Yörük, Turkish J. of Earth Sci. 17, 405 (2008)

3. T. Taymaz, O. Tan, S. Yolsal, The Proceedings of IWAM04, (Mizunami Japan 2012)

4. A. Öcal Kastamonu Eğtim Dergisi. 15, 1 (2007)

5. F. Aydın, Turkish Studies, 5, 801 (2010)

6. E. Buluş-Kırıkkaya, O. Çakın, O., B. İmalı, \& E. Bozkurt, Pro.Soc. Beh. Sci. 15, 2305 (2011)

7. E. Buluş-Kırıkkaya, A. Oğuz-Ünver, \& O. Çakın, Necatibey Eğt. Fak. Elekt.Fen ve Mat. Eğt. Der. 5, 24 (2011)

8. C. Laçin-Şimşek, Jour.of Env. \& Sci.Edu. 2, 14 (2007).

9. A. Nalçacı, World Applied Sci. Jour. 12, 1422 (2011).

10. M. Cin, H. Kara, A. Demir, International Earthquake Symposium (Kocaeli 2009)

11. M. Cin, Marmara Coğrafya Dergisi 22, 70 (2010)

12. J. Dove, Res. Papers in Edu. 13, 183 (1998)

13. S. Rakkapao, K. Arayathanitkul, P. Pananont, R. Chitaree, (2012) 
14. K. E. K. Ross, T. Schuell Northeastern Educational Research Association, (Ellenville, NY 1990)

15. B. Aksoy, Jour. of World of Turks 5, 247 (2013)

16. B. Aksoy, E. Sözen, Uşak Üni. Sos. Bil. Der. 7, 279 (2014)

17. F. Aydın, ve M Coşkun, Int.Jour.of the Physical Sci. 5, 1324 (2010)

18. H. Demirkaya, Türkiye Sos. Araş.Der. 3, 38 (2007)

19. F. Savaşcı-Açıkalın, H. Uludüz, Asia-Pacific Forum on Sci.Learn. and Teach. 14, 1 (2013)

20. Ü. Özdemir, M. Ertürk, İ Güner, M. K. Koca, Doğu Coğ.Der. 7, 109 (2002)

21. A. D. Leather, Geology Teaching, 12102 (1987).

22. W. C. Philips, Science Teacher 5821 (1991)

23. S. Altay, Yüksek Lisans Tezi, Abant İzzet Baysal Üni.Sosyal Bil. Enst. (2008) 